\title{
Evaluating the time of the visual scene and its relationship to the values of some biochemical variables in the performance of the main section of the spiking and blocking skills in the volleyball
}

\author{
HAMZA FADHIL HASAN 14 , YA'ARUB DAIKH BAQI ABDUL ${ }^{2}$ \\ ${ }^{1}$ Ministry of Education, Basra Education, Iraq \\ ${ }^{2}$ College Physical Education, University of Basra, Iraq
}

\begin{abstract}
The biomechanical examination is worried about contemplating development and adds to expanding the degree of specialized players because of the utilization of present-day programming for kinematic investigation and the innovation of mechanical gadgets that have added to improve the specialized exhibition capacities of the players and the mentors follow the logical establishments in the improvement of execution strategies and assessment of the visual scene, and this visual kinematic measure in the divisions of a second expects us to Consider and assessing their planning and body development conditions in the fundamental segment of the two aptitudes and creating mathematical qualities that give an image of execution at these significant minutes as expected. The investigation meant to distinguish the assessment of the hour of the visual scene and its relationship with the estimations of some biochemical factors in the exhibition of the fundamental segment of the abilities to spike and impeding with volleyball. The exploration issue is the speed of development of the rival player and the ball and the trouble of focusing on it during self-survey by the mentor, explaining perspectives identified with centring consideration, knowing where the ball arrived from the stomach, the development of the player's arm, and picking the kind of hit or impeding the ball and its course. The two analysts utilized the spellbinding technique by the strategy for looking over on an example of the Iraqi public cooperative individuals for the year (2019-2020), and the main ends are that the player who plays out the of obstructing and pounding strikes and has an evaluation of the right visual scene can hit and repulse the ball because of the development of the arms and hands towards the ball well.
\end{abstract}

Keywords: Visual scene; Spiking; Blocking; Biochemical variables.

Cite this article as:

Hasan, H.F., \& Abdul, Y.D.B. (2021). Evaluating the time of the visual scene and its relationship to the values of some biochemical variables in the performance of the main section of the spiking and blocking skills in the volleyball. Journal of Human Sport and Exercise, 16(3proc), S1434-S1443. https://doi.org/10.14198/jhse.2021.16.Proc3.59

Corresponding author. Ministry of Education, Basra Education, Iraq.

E-mail: hamza68fadel@gmail.com

Abstract submitted to: Winter Conferences of Sports Science. Costa Blanca Sports Science Events, 22-23 March 2021. Alicante, Spain.

JOURNAL OF HUMAN SPORT \& EXERCISE ISSN 1988-5202.

(c) Faculty of Education. University of Alicante.

doi:10.14198/jhse.2021.16.Proc3.59

S1434

| 2021| Proc3 | VOLUME 16

(c) 2021 University of Alicante 


\section{INTRODUCTION}

The handy advancement of the worldwide cooperative people is a consequence of the utilization of logical techniques and strategies in expertise, physical, mental and arranging preparing, and that the development device of volleyball players needs ceaseless direction and preparing joined by "tests and principles to decide the degree of its encouraging" (Ahmed Issa - Subhi Ahmed, 2012), and the utilization of present day programming The innovation of mechanical gadgets added to improving the specialized exhibition capacities of the players at the degree of visual reasoning and dynamic about body positions as per the information of involvement, experience and continuous perception of the player, and his capacity to react to data that is shipped off the cerebrum (Zaki Al-Khatayba, 1996), and that the assessment of specialized execution from Before mentors to know the aftereffects of their preparation and get exact data from those gadgets and instruments utilized in kinematic and biomechanical examination (Batman Abdel Wahab - Wehbe Alwan, 2019), consequently expanding the players' observation from the visual and active side, and the capacity to control development measurements is dictated by the exactness of engine sensations and visual recognitions, and that the aptitudes of squashing and hindering are what bring authority throughout play as needs (Bob Jersey (translated by Raisan Khraibet and Abdel Zahra Hamidi), 1990).

To give dynamic, spatial and transient pictures and details for body developments and the particular strategy for completing the development during the exhibition of the principle area, where the devastating hitting requires the player to coordinate the ball powerfully and away from the hindering or hitting it against the impeding so it goes outside the arena to get a point, and the player of the obstructing must watch and follow On the hitter, the presser arm, and the bearing of revolution of the arm and the lift, the point of weight will be resolved, and when the ball hit by the aggressor is near the net and hence it is better for the player to hinder the when defied by the arms and rule out the ball to pass and frame a "empty" surface and high over the net The snapshot of contacting the ball and pushing ahead from the wrist joint to hit the ball in the rival's court (Diebold, B. Van Dalen, 1962), notwithstanding that, the ball is outwardly observed forcefully while in trip with the assaulting player's development when drawing nearer and climbing (Raisan Khuraibet, 2017), and this relies upon quickening visual similarity to beat timing issues for right on time or late ascent or upon contact with the ball noticeable all around, just as visual similarity and nearness offices for fast and exact visual transformation to separate and the pattern, and consideration cooperates with tactile discernment and memory in dynamic (Zaki Muhammad Hassan, 2004), and this visual-kinematic measure in the subsequent parts expects us to contemplate it and assess its time and body development conditions in the fundamental piece of the two abilities and create values An advanced picture that gives an image of the presentation at these time and development minutes as per the two aptitudes procedures so as to explain the perspectives identified with zeroing in on the player's development in acquiring precise data dependent on the investigation of specialized execution, and that the speed of the rival player's development and the ball and the trouble of focusing on it during self-survey by the mentor and explaining viewpoints Identified with the visual scene, knowing the player's development, picking the sort of hitting or impeding the ball and its heading, and assessing the hour of the visual scene without anyone else perception by the mentor and its relationship to progress and the assessment of some biochemical factors is troublesome, just as the absence of premium in the hour of the visual scene and knowing its impact on the achievement of the assault is an issue that many endure Of the players, and this needs to examine and break down cautiously the expertise and provide mathematical qualities so as to explain the degree of the player's revenue in the hour of the visual scene The presentation of the primary segment for every aptitude, and from the above is a difficult that made the scientists address and study so as to convey execution data to mentors and build up the degree of their players (Saad Hammad Al-Jumaili, 2006). 


\section{The objective of the study}

1. Evaluating the time of the visual scene of the player who performs the main part of the skills of spiking and blocking with volleyball.

2. Identify the relationship between the time of the visual scene and the successful performance of the skills of spiking and blocking volleyball.

3. Identify the relationship between the time of the visual scene and the evaluation of some biochemical variables in the performance of the main section of the skills of spiking and blocking skills in volleyball.

\section{METHODS AND STRUCTURE}

\section{The experimental approach to the problem}

The enlightening methodology was utilized by the technique for study examines and correlational relations. The engaging methodology is one of the normally utilized exploration strategies, which incorporates different techniques, including study, social relationship study, and similar alumni contemplate. Social examinations, in which the measure of connections between the information is known, and it shows how much one variable is identified with another (Saad Muhammad - Luay Ghanem, 1985).

\section{Participants}

The exploration test comprised of (6) players of the Iraqi public volleyball crew for the year (2019-2020), to guarantee the homogeneity of the example in certain factors that may influence the eventual outcomes, and utilize the coefficient of variety, and it was discovered that the estimation of the math means and the standard deviation of length (193.50) - 2.428) with a distinction coefficient of (0.0125), while the number juggling means and the standard deviation of the mass came to $(84.500-1.378)$ and with a distinction coefficient of $(0.0163)$.

\section{Procedure}

The specialists utilized Arabic and unfamiliar sources and references, a Japanese-made camcorder, Casio Exilim ex-fh20 $9.1 \mathrm{mp}$ computerized 20x $1000 \mathrm{fps}$, a PC type dell Inspiron cor i7, a stand and lawful plane balls. The example was shot in the delegate corridor of the Olympic Panel and the camera was put at a level separation $(6 \mathrm{~m}$ ) estimated from the vertical projection of the camera to the situation of the player's standing and at tallness of $(1.40 \mathrm{~m})$ estimated from the focal point of the focal point to the outside of the earth. The factors to be examined were broke down through the (dartfish group master 5.5) program.

\section{Measures}

The presentation of spiking was from focus (4) and impeding from focus (2). The visual scene of the major part in the primary area (the focal point of the examination) was estimated for the two abilities by ascertaining the time-frame in which the player takes a gander at the other player, his position, the situation of the arms according to the striking player and how to catch The protector of the ball for the assaulting player and the evaluation is made to help the visual scene through the accomplishment of the able execution. Every player was given (5) endeavours at spiking and the hindering, and the achievement of the presentation was assessed. A score and when contacting the impeding and intersection it gets (5) degrees, while it gets zero in case of the obstructing accomplishment in capturing and plummeting in the group field, however on account of the hindering, the assessment of the achievement of the hindering was on a contrary premise (10) degrees on account of the achievement of the total impending cycle) 5) scores on account of contact and intersection the net (zero) if the hit ball was not moved by the aggressor. All endeavours were analysed and the hour of the two visual scenes was determined to guarantee the achievement relationship of obstructing or assaulting 
the hour of the visual scene, this was concentrated to encourage the cycle. Assessment of the scene and its effect on progress.

A Sony hdr-xr520 camera was utilized for close imaging for the two players and was set a way off of ( $3 \mathrm{~m})$ from the exhibition territory to furnish a more clear and closer picture with a statue of $(2.50 \mathrm{~m})$ and was introduced on the segment close to the presentation region. Variable season of the visual scene of the devastating hit by ascertaining the time it takes for the striker to take a gander at the obstructing after the ball arrives at the tallness of the hitting for the assaulting player until the ball is hit, just as for the major part accountable for the hindering activity as the time in which the player takes a gander at the ball right now it is hit by the aggressor is determined to the snapshot of intersection The ball or its impeding, just as the hip point estimated from the line drawn from the hip joint to the shoulder joint and the line attracted from the hip to the knee joint and the point of the shoulder when playing out the devastating or obstructing cycle, and it is estimated from the line drawn from the shoulder joint to the elbow joint and the line drawn from the joint The shoulder and the hip joint were estimated, and the hip joint was estimated.

The wrist point of the point between the line attracted from the metacarpal to the hand and the line drawn and from the wrist was estimated from the back and the elbow joint in the two abilities, and the striking arm point was estimated with the pivot A The length existing apart from everything else of the hit in the devastating hit is through the point-shaped between the hub of the length of the item and the expansion of the striking arm, just as for the arm near the ball. Concerning the separation between the two hands, it was estimated by the separation between the two thumbs. Concerning the variable of the greatest tallness of the purpose of contact, the good ways from the beginning the focal point of the ball is estimated.

\section{Analyses}

After the results of the research were obtained, statistical treatments were performed using the statistical program (SPSS) version (22). means, standard deviations, and Pearson correlation (Sarah Abd al-Karim alFadhli, 2010) were extracted between the visual scene variable and the evaluation results, based on which the extent of the time effect The visual scene is based on the performance results, and the results were based on the level of significance (.05), as well as between the visual scene time and the biochemical variables.

\section{RESULTS}

Table 1. Shows the performance evaluation of the spiking skill, blocking, visual scene time for the two skills, and the Pearson correlation coefficient.

\begin{tabular}{|c|c|c|c|c|c|}
\hline Variables & Mean & $\begin{array}{c}\text { Std. } \\
\text { Deviation }\end{array}$ & Correlations & Sig. & $\mathbf{N}$ \\
\hline Spiking rating & 6.2000 & 3.89444 & & & 30 \\
\hline $\begin{array}{l}\text { The time of the visual scene when } \\
\text { performing the main section of the } \\
\text { spike }\end{array}$ & 0.0264 & 0.00757 & $.577^{\star *}$ & .003 & 30 \\
\hline Evaluating the blocking & 5.4000 & 4.54606 & & & 30 \\
\hline $\begin{array}{l}\text { The time of the visual scene when } \\
\text { performing the main section of the } \\
\text { block }\end{array}$ & 0.0248 & 0.00510 & $.453^{*}$ & .032 & 30 \\
\hline
\end{tabular}


To achieve the first and second objective of the study, which is the evaluation of the visual scene, the relationship between the time of the visual scene and the success and accuracy of performance was studied through the correlation coefficient of Pearson and as shown in Table 1.

It was found that the visual scene has an important relationship to success, so it became possible to evaluate the visual scene. By the extent of the success of the performance in the skills of blocking and attacking, this is a good indicator to some extent and based on the success achieved in hitting the spiking and the of blocking. A degree and this is within an average level, and this means that the players do not focus on the visual viewing process before directing the ball and do not pay attention to the shape of the blocking by a large amount as this means giving room to the player who is blocking from changing the position of the hands, which makes it difficult for the attacking player to carry out the attack and increase This issue is if the attacker does not take sufficient time to know the change in the blocking, especially since the distance between the net and the attacking player provides a better field of vision, and the attacking player is the one who controls this (Talha Hussam El-Din, 2014).

Despite this, the time for the visual scene was relatively low, and Failure rates increase dramatically if there is a blocking player who looks at the ball correctly and changes the position of the arms and the evaluation is an indicator of performance and that the visual scene is present. Also, the success of the attack is not completely dependent on the visual scene, so the researchers work to be Filming directly on the player's face to ascertain the period of the visual scene and the extent of its influence in that while putting in the calculations the ability of the blocking and the capabilities of the player in charge. While the evaluation of the blocking's performance was within an acceptable level and the players do not take into account looking at the ball in the performance of the blocking, which provides an opportunity for the attacking player to strike far from the blocking (Adel Abdul-Basir Ali, 1998). The block was low, which means several reasons, including not seeing the hit ball in one way or another, and if it is looked at, it is in a very short time, then it changes its gaze towards the bottom, and this is wrong by many of the players on the blocking, and this may be due to mistakes made in previous stages that caused the ball to hit the face This is due to an exaggerated improvement at times, which will negatively affect future performance and the failure to correct this psychological path by the player and coach separately, whether it leads to the accumulation of this situation and occasional incorrect learning leads to such a situation. The first line of defence usually consists of (5) classes on which to determine the efficiency of the blocking.
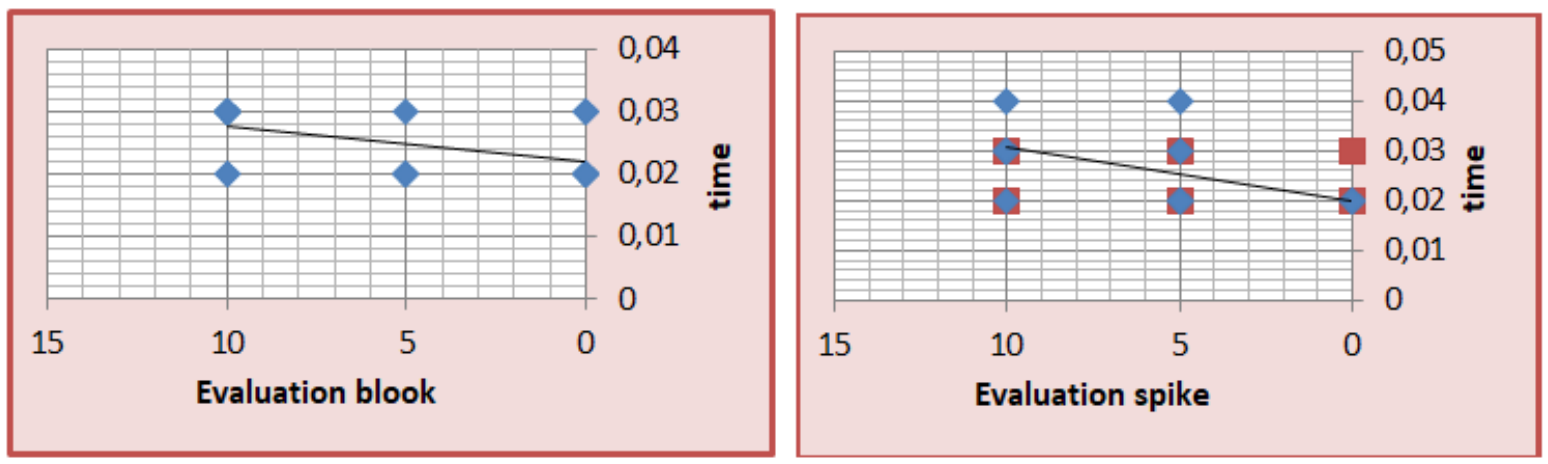

Figure 1. Shows the relationship between visual scene time and evaluation in the skills of spiking and blocking. 


\section{Presentation and discussion of the results of the correlation between the visual scene and some biochemical variables of the skill of spiking}

Table 2. Show the values of the mean and the standard deviations of the visual scene and the values of some biochemical variables in the main section of the performance of the skill spiking.

\begin{tabular}{lccc}
\hline Variables & Mean & $\begin{array}{c}\text { Std. } \\
\text { Deviation }\end{array}$ & N \\
\hline The time of the visual scene when performing the main section & 0.0264 & 0.00757 & 30 \\
The angle of the hip joint & 165.0860 & 3.58639 & 30 \\
The shoulder angle of the striking arm & 173.7360 & 2.23698 & 30 \\
Wrist joint angle & 184.3680 & 1.33314 & 30 \\
The angle of the striking arm with the longitudinal axis of the moment of & 43.2140 & 2.37643 & 30 \\
the strike & 3.0872 & 0.06262 & 30 \\
The maximum height of the point of contact with the ball & 0.9364 & 0.10503 & 30 \\
The distance between hitting and blocking the ball & & & \\
\hline
\end{tabular}

Table 3. Shows the Pearson correlation coefficient between the time of the visual scene and the biochemical variables in the main section of the spiking strike.

\begin{tabular}{|c|c|c|c|c|c|c|c|}
\hline Variables & & $\begin{array}{l}\text { The } \\
\text { angle of } \\
\text { the hip } \\
\text { joint }\end{array}$ & $\begin{array}{l}\text { The } \\
\text { shoulder } \\
\text { angle of } \\
\text { the striking } \\
\text { arm }\end{array}$ & $\begin{array}{l}\text { Wrist joint } \\
\text { angle }\end{array}$ & $\begin{array}{l}\text { The angle of } \\
\text { the striking } \\
\text { arm with the } \\
\text { longitudinal } \\
\text { axis of the } \\
\text { moment of } \\
\text { the strike }\end{array}$ & $\begin{array}{l}\text { The } \\
\text { maximum } \\
\text { height of } \\
\text { the point of } \\
\text { contact with } \\
\text { the ball }\end{array}$ & $\begin{array}{l}\text { The distance } \\
\text { between } \\
\text { hitting and } \\
\text { blocking the } \\
\text { ball }\end{array}$ \\
\hline \multirow{2}{*}{$\begin{array}{l}\text { The time of } \\
\text { the visual } \\
\text { scene }\end{array}$} & $\begin{array}{l}\text { Pearson } \\
\text { Correlation }\end{array}$ & 0.007 & $0.522^{* *}$ & 0.166 & $0.571^{* *}$ & $-0.295-$ & $0.816^{* *}$ \\
\hline & $\begin{array}{l}\text { Sig. (2-tailed) } \\
N\end{array}$ & $\begin{array}{c}0.975 \\
30\end{array}$ & $\begin{array}{l}.007 \\
30\end{array}$ & $\begin{array}{c}0.429 \\
30\end{array}$ & $\begin{array}{c}0.003 \\
30\end{array}$ & $\begin{array}{l}0.153 \\
30\end{array}$ & $\begin{array}{c}0.000 \\
30\end{array}$ \\
\hline
\end{tabular}

Table (3) shows that there is a correlation between the time of the visual scene and the variable of the shoulder angle of the striking arm in the spiking strike, since the sight of the blocking is what provides the path of the ball or the angle at which the ball will be struck and in the presence of muscular and nervous compatibility and the explosive force that reaches its maximum to the palm to guide The ball is in the opponent's court (Ali Salloum, Jawad Al-Hakim, 2004), as the height of the blocking and its clear viewing gives the player the ability to determine the hitting area if it is for the areas near the stadium or far, and if the block is high, then the hitting will be far from the blocking and to the sides or try For the player to increase the extension of the striking arm until he uses the striking from the top of the blockings, so a good relationship appeared between the time of the visual scene of the player hitting the shoulder angle of the hitting arm. It was also found that there is a correlation between the time of the visual scene and the angle of the nonstriking arm from the longitudinal axis, and this means that the direction of the arm is outward away from the longitudinal axis of the body of the hitting player that the ball will be directed to the side of the blocking away from it and both sides so that it works to move the arm away from the longitudinal axis To maintain the balance of the body and not to rotate in the opposite direction as a result of the movement of the striking arm according to Newton's law in rotational movements (Ya'rub abdulbaqi data, hamza Fadhil Hasan), because the resistance to the rotating motion needs to remove the non-striking arm to increase the moment of inertia (Qasim Hassan, Iman Shaker, 1998), and this dimension increases if the blocking is double, meaning that 
the ball is directed towards areas of the side of the playing field and areas close to the net, but this requires a suitable height and elevation for such direction.

It also turns out that there is a relationship between the time of the visual scene and the horizontal distance between the blocking and the point of hitting the ball, and this means that the appropriate distance from the blocking allows a better field of view, thus increasing the ability of the hitter to direct the ball away from the blocking. In any case, proximity to the blocking reduces the time of the scene. The visual is the moment of directing the ball, as the optical curb time decreases. The synchronization between the blocking game and the attacking player depends mainly on the start of the attacking player, the quality of the attack and the height of his attack since correctly starting the advancement and at the appropriate time is a decisive factor in reaching the appropriate height at the appropriate time to intercept the ball as the distance from which the ball strikes also have an effect and this varies according to For the ball place prepared by the preparer.

\section{Presentation and discussion of the results of the correlation between the visual scene and some biochemical variables of blocking skill}

Table 4. Show the values of the mean and the standard deviations of the visual scene and the values of some biochemical variables in the main section of the performance of the blocking skill.

\begin{tabular}{lccc}
\hline Variables & Mean & Std. Deviation & $\mathbf{N}$ \\
\hline The time of the visual scene when performing the main section & 0.0248 & 0.00510 & 30 \\
The angle of the hip joint & 159.2960 & 2.52281 & 30 \\
Shoulder angle of the left arm & 127.7840 & 2.33304 & 30 \\
Wrist joint angle & 163.3800 & 1.49304 & 30 \\
The angle of the proximal arm of the ball with the longitudinal axis & 133.3000 & 2.40052 & 30 \\
The distance between the two hands & 16.8648 & 1.52792 & 30 \\
The maximum height of the point of contact with the ball & 2.7608 & 0.04051 & 30 \\
\hline
\end{tabular}

Table 5. Shows the Pearson correlation coefficient between the time of the visual scene and the biochemical variables in the main section of the block.

\begin{tabular}{|c|c|c|c|c|c|c|c|}
\hline Variables & & $\begin{array}{l}\text { The } \\
\text { angle of } \\
\text { the hip } \\
\text { joint }\end{array}$ & $\begin{array}{l}\text { Shoulder } \\
\text { angle of } \\
\text { the left } \\
\text { arm }\end{array}$ & $\begin{array}{l}\text { Wrist } \\
\text { joint } \\
\text { angle }\end{array}$ & $\begin{array}{l}\text { The angle of } \\
\text { the proximal } \\
\text { arm of the } \\
\text { ball with the } \\
\text { longitudinal } \\
\text { axis }\end{array}$ & $\begin{array}{l}\text { The } \\
\text { space } \\
\text { between } \\
\text { the two } \\
\text { hands }\end{array}$ & $\begin{array}{l}\text { The maximum } \\
\text { height of the } \\
\text { point of } \\
\text { contact with } \\
\text { the ball }\end{array}$ \\
\hline $\begin{array}{l}\text { The time of } \\
\text { the visual }\end{array}$ & $\begin{array}{l}\text { Pearson } \\
\text { Correlation }\end{array}$ & $0.866^{* *}$ & $0.823^{* *}$ & 0.161 & $0.878^{* *}$ & $0.862^{* *}$ & 0.223 \\
\hline $\begin{array}{l}\text { scene when } \\
\text { performing }\end{array}$ & Sig. (2-tailed) & 0.000 & 0.000 & 0.442 & .000 & 0.000 & 0.285 \\
\hline $\begin{array}{l}\text { the main } \\
\text { section }\end{array}$ & $\mathrm{N}$ & 30 & 30 & 30 & 30 & 30 & 30 \\
\hline
\end{tabular}

Table (5) shows that there is a correlation between the visual scene variable and the hip joint angle variable, and this is because the position of the torso is a helpful factor in increasing the range of vision and the visual scene and that lowering or bending the hip means that the head is tilted slightly downward, which increases the difficulty of vision. The visual or reduces the time of the visual scene of the ball hit by the attacking player, and thus the player's body depends on the information surrounding the sensory receptors in the muscles and 
joints on which the body position, direction and movement rates work (Muhammad Lotfi Al-Sayed Hassan, 2011).

It is evident from the same table that there is a correlation between the visual scene variable and the shoulder angle variable for the left arm, and the arm was determined here, since the block was from the centre (2) as the exaggerated bending and insertion of the arms in the opposing team's arena prevented, in one way or another, from increasing the time of the visual scene. As this means that the height is exaggerated, and therefore the blocking player will take more precautions and lower the head before making great sure of the movement and direction of the ball, and this reduces the efficiency of the blocking, and that the shoulder joint forms an axis to stabilize the force the moment the strong ball is blocked and most of the muscles of the chain work The kinematics are on more than one joint, and the blocking must emphasize the ball hit by the opponent, i.e. left, "so that it faces the flight path of the ball" (Wadih Muhammad Al-Morsi, 2017).

It was also found that there is a relationship between the time of the visual scene and the angle of the proximal arm of the ball with the longitudinal axis, especially since the correct view of the ball enables the player to move the arm towards the path of the movement of the ball, especially if the hitting player directs the ball to the sides of the blocking if the vision of the ball's direction is correct. (Yacoub Abdel-Baqi - Hamza Fadel, 2020) Allows the player in the blocking operation to move the arms to the side towards the ball in order to intercept its movement, and the duration of the kinetic prediction depends on the time between striking the ball from the attacking player until it reaches the blocker player (Kuan et al., 2018). There was also a correlation between the time of the visual scene and the variable of the distance between the two hands, and this is because the player increases that distance if he notices that the attacking player is hitting the ball to the sides of the blocking and that the change is made by the attacking player through the movement of the arm away from The longitudinal axis of the body of the hitting player, and therefore increasing the distance between the hands is effective while maintaining the tension in the fingers so that the ball does not slacken and the ball crosses it, so coaches usually recommend players to maintain the tensile strength in the fingers of the hands, and in general the volleyball game is one of the games that need to be Great timing and correct prediction (Raúl Hileno et al., 2018).

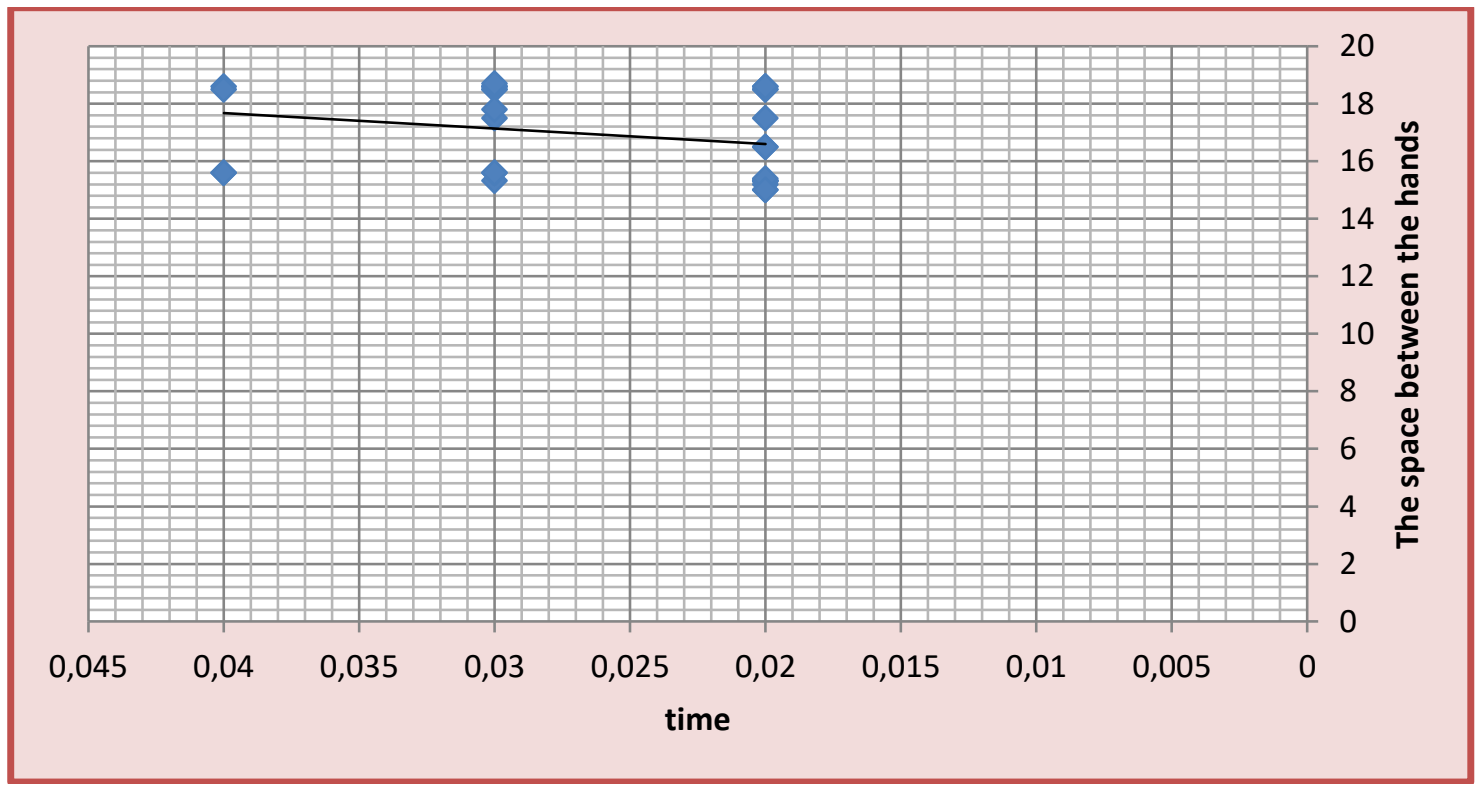

Figure 2. Shows the relationship between the time of the visual scene and the distance between the hands. 


\section{CONCLUSIONS}

1. It was found that the time of the visual scene is closely related to the results of the accuracy evaluation in the performance of the skills of striking and blocking, as it is an important element in achieving better performance.

2. The visual scene is related to the variable of the shoulder angle of the hitting arm, the variable of the angle of the hitting arm with the longitudinal axis at the moment of hitting, and the variable distance between the hitting the ball, which obtained a very high correlation and repelling it, and causes a change in these values when performing the spiking skill.

3. It was found that the visual scene correlates with making a change in the variable values of the hip joint angle and the shoulder angle of the left arm, the angle of the proximal arm of the ball with the longitudinal axis, the distance between the hands, and the correlation values were high and were not less than (0.80).

\section{REFERENCES}

Adel Abdul-Basir Ali (1998). Biomechanics and the integration between theory and practice in the mathematical field, 2nd ed., Al Kitab Center for Publishing, Cairo, Al Kitab Center for Publishing, 112 pp.

Ahmed Issa - Subhi Ahmed (2012). Volleyball (Skills - Training - Injuries), 1st Edition, Arab Society Library for Publishing and Distribution, pg. 59.

Ali Salloum, Jawad Al-Hakim (2004). Tests and measurement in the field of sports, Al-Qadisiyah University, (269-295).

Batman Abdel Wahab - Wehbe Alwan (2019). Biomechanical evaluation of movement in sport and exercise, Jordan, Amman, p. 36.

Bob Jersey (translated by Raisan Khraibet and Abdel Zahra Hamidi) (1990). Higher Education Press, pp. 49-50.

Diebold, B. Van Dalen (1962). Research Methods in Education and Psychology, translated by Muhammad Nabil Nofal and others, Cairo, The Anglo-Egyptian Library, 317-348.

Kuan, Y. M., Zuhairi, N. A., Manan, F. A., Knight, V. F., \& Omar, R. (2018). Visual reaction time and visual anticipation time between athletes and nonathletes. Malaysian Journal of Public Health Medicine, 1, 135-141.

Muhammad Lotfi Al-Sayed Hassan (2011) The Distinguished Visual Character in Volleyball, 1st Edition, Cairo, Book Center for Publishing, pg. 145.

Qasim Hassan, Iman Shaker (1998). Principles of the mechanical foundations of mathematical movements, first edition, Amman, Dar Al-Fikr for printing, publishing and distribution, pp. 254-287.

Raisan Khuraibet (2017). Physical fitness, 1st floor, Cairo, Arab Thought House for Printing and Publishing, p. 177.

Raúl Hileno et al. (2018). What are the Most Widely used and Effective Attack Coverage Systems in Men's Volleyball.journal of human kinetic Published online, 62, 111-121. https://doi.org/10.1515/hukin-2017-0163

Saad Hammad Al-Jumaili (2006). Volleyball - Skill and Planning Preparation, Amman, Zahran House for Publishing and Distribution, p. 246.

Saad Muhammad - Luay Ghanem (1985). Volleyball between theory and practice, Mosul, University Press, p. 3.

Sarah Abd al-Karim al-Fadhli (2010). Biomechanical Applications in Sports Training and Motor Performance, 2nd Edition, pg. 186. 
Talha Hussam El-Din (2014). ABCs of Movement Sciences - Functional Descriptive Kinesiology, 1st Edition, Cairo, Modern Book Center, pg.73.

Wadih Muhammad Al-Morsi (2017). Kinetic Analysis Technology "and Technically", p. 61.

Yacoub Abdel-Baqi - Hamza Fadel (2020). Volleyball, Skills - Education - Biomechanical Applications, 1st Edition, Amman, Al-Wadah Publishing House, p. 254.

Ya'rub abdulbaqi data, hamza Fadhil Hasan: The synchronization mechanism between the movement of the blocking player and the attacking player for two different heights of volleyball setup and some, International Journal of Psychosocial Rehabilitation, vol24, issue3, 2020.

Zaki Al-Khatayba, A. (1996). Encyclopedia of Modern Volleyball, 1st Edition, Amman, Dar Al-Fikr, p. 162.

Zaki Muhammad Muhammad Hassan (2004). Visual Vision Skills for Athletes, Egypt, The Egyptian Library for Printing and Publishing, p.99.

\section{(c)}

This work is licensed under a Attribution-NonCommercial-NoDerivatives 4.0 International (CC BY-NC-ND 4.0). 